\title{
Reactivation of Immanent Herpes Group Virus
}

\begin{abstract}
Key words: herpes virus, Epstein-Barr virus, drug induced skin rash, herpes zoster rheumatoid arthritis, hypersensitivity syndrome
\end{abstract}

Recent modern molecular biology techniques indicate the involvement of herpes viruses in the pathogenesis of some diseases. Herpes group viruses include cytomegalovirus, Epstein-Barr virus (EBV), herpes simplex 1 or 2, varicella zoster virus, human herpes virus (HHV)-6, HHV-7 and HHV-8. These viruses are transferred by human contact and cause a primary infection, which commonly does not show clinical signs and may exist even for years in a latent state in healthy individuals by means of suppressive immune regulation. Nonetheless, those viruses may be reactivated by the dysregulation of the host immune system or possibly by virus mutations. There is a great deal of evidence of the association of herpes simplex virus and recurrent erythema multiforme. This association has been supported by clinical and laboratory studies. Huff and Weston indicated that patients had a history of herpes simplex virus infection proceeding their as analyzed episode and their sera had antibodies to this virus by enzyme immunoassay (1). Furthermore, they demonstrated that herpes simplex virus antigen was detected in the skin biopsy specimens by an indirect immunofluorescent technique with a monoclonal antibody to the type common human simplex virus glycoprotein $\mathrm{gB}$ around keratinocytes in the epidermis.

Brice et al demonstrated herpes simplex virus (HSV) DNA in the cutaneous lesions of erythma multiforme, by means of polymerase chain reaction and, by in-situ hybridization with ${ }^{35} \mathrm{~S}$-labeled HSV-RNA probe within the epidermis (2). Many reports have discussed the role of viral infection and drug induced skin rash, and showed clinical evidence that cutaneous rashes are observed in more than $90 \%$ of patients given ampicillin in patients with infectious mononucleosis whereas usually are observed in less than $15 \%$ in patients without it (3) and that an extraordinary high incidence of Stevens-Johnson syndrome in patients infected with human immunodeficiency virus (4).

Kunishige et al (5) in this journal described that Salazosulfapirigine induced hypersensitivity syndrome associated with reactivation of human herpes virus 6 .

See also p 203.

A hypersensitivity syndrome has been reported with the administration of a limited number of drugs, such as allopurinol, dapsone, minocycline and phenytoin (6), suggesting that the specified structure of drug involves a hypersensitivity syndrome or a latent virus reactivation. Even though the precise mechanism by which viral infection causes the drugassociated skin rash remains unclear, it has been suggested that the regulatory gene mutation defines the reactivation of herpes simplex virus latency (7).

A reactivation of immanent virus may be a crucial event for the development of a severe drug-induced hypersensitivity syndrome.

The ampicillin rash appeared in patients only in primary EBV infection but not in the recovery period (3). This report suggested that skin rash may be incriminated by the EB virus reactivation. We have often observed herpes zoster or trigeminal nerve paralysis, which is thought to be reactivation of herpes simplex virus in patients with rheumatoid arthritis (RA). Indeed, it has been reported that there is an increased subsequent risk of RA in patients diagnosed with herpes zoster $(8,9)$.

Primary EB virus infection is characterized by atypical lymphocytes which are the CD8+ T cell subset. These CD8+ $\mathrm{T}$ cells play the role of MHC-restricted virus-specific cytotoxic $\mathrm{T}$ cell function. We examined the synovial tissues from 34 patients with RA and from 20 patients with osteoarthritis (OA), and from one patient with psoriatic arthritis as controls, for evidence of the EBV by in-situ hybridization. The specimens were also tested by immunoperoxidase staining for expression of EBV nuclear antigen (EBNA)-2 and latent membrane protein (LMP)-1. EBV-encoded small RNA1 (EBER) was demonstrated in synovial lining cells from eight $(23.5 \%)$ out of 34 RA patients but in none of $20 \mathrm{OA}$ patients $(p<0.05)$ nor in the one psoriatic arthritis patient. Furthermore, LMP-1 was also detected in synovial lining cells. Nevertheless, EBNA-2 was not demonstrated in such lesions. The incidence of EBV existence in synovial lining cells with severely infiltrated lymphocytes tended to be higher than that in moderately infiltrated ones (10).

In a recent study searching for the causative gene of $\mathrm{X}$ linked lymphoproliferative syndrome, the gene linked to EBV-specific cytotoxic T cells or NK cell-mediated cytotoxic activity to EBV-infected cells was discovered, and its product is now referred to as signaling lymphocyticactivation molecule-associated protein (SAP) or Src homology 2 domain-containing protein (SH2D1A) (11). We have found that the expression level of SAP transcripts in peripheral leukocytes of RA patients was significantly lower than that of normal individuals $(\mathrm{p}=0.0007)$, that of inactive syste- 


\section{LBS with Hyperparathyroidism}

mic lupus erythematosus or that of chronic renal diseases. There was no mutation in the coding region of SAP cDNAs derived from peripheral leukocytes of RA patients. The decreased expression of SAP transcripts in peripheral leukocytes or T cells of RA patients might lead to the failure of the immune system to eliminate the EBV-infected synovial lining cells in joints of RA patients (12).

Taken together, the reactivation of latent virus might be due to the mutation of latent virus or due to the decreased regulatory function of human genes for the drug-induced rash.

Shigemasa SAWADA, MD**** and Masami TAKEI, MD**

*Department of Medicine, Nerima Hikarigaoka Nihon University Hospital, 2-11-1 Hikarigaoka, Nerima-ku, Tokyo 179-0072 and **Department of Medicine, 1st Department of Medicine, Nihon University School of Medicine. 30 Kamimachi, Ohyaguchi, Itabashi-ku, Tokyo 173-8610

\section{References}

1) Huff JC, Weston WL. Recurrent erythema multiforme. Medicine (Baltimore) 68: 133-140, 1989.

2) Brice SL, Krezemien D, Weston WL, Huff JC. Detection of herpes simplex virus DNA in cutaneous lesions of erythema multiforme. J Invest Dermatol 93: 183-187, 1989.

3) Pullen $\mathrm{H}$, Wright $\mathrm{N}$, Murdoch JM. Hypersensitivity reactions to antibacterial drugs in infectious mononucleosis. Lancet 2: 1176-1178, 1967.
4) Rzany B, Mockenhaupt M, Stocker U, Hamouda O, Schopf E. Incidence of Stevens-Johnson syndrome and toxic epidermal necrolysis in patients with the acquired immunodeficiency syndrome in Germany. Arch Dermatol 129: 1059, 1993 (letter).

5) Kunisaki Y, Goto H, Kitagawa K, Nagano M. Salazosulfapyridine induced hypersensitivity syndrome associated with reactivation of humanherpes virus 6. Intern Med 42: 203-207, 2003.

6) Mizukawa Y, Shiohara T. Virus-induced immune dysregulation as a triggering factor for the development of drug rashes and autoimmune diseases: with emphasis on $\mathrm{EB}$ virus, human virus 6 and hepatitis $\mathrm{C}$ virus. J Dermatol Sci 22: 169-180, 2000.

7) Leib DA, Coen DM, Bogard CL, Hicks KA, Yager DR, Knipe DM. Immediate-early regulatory gene mutants define different stages in the establishment and reactivation of herpes simplex virus latency. J Virol 63: 759-768, 1989.

8) Ragozzino MW, Kurland LT. Subsequent risk of rheumatoid arthritis in patients diagnosed with herpes zoster. Lancet 16; 2 (8303): 884, 1982 (letter).

9) Campalani E, Meenagh GK, Finch MB. Case Number 22: An interesting case of herpes zoster in rheumatoid arthritis. Ann Rheum Dis 61: 102, 2002.

10) Takei M, Mitamura K, Fujiwara S, et al. Detection of Epstein-Barr virus-encoded small RNA 1 and latent membrane protein 1 in synovial lining cells from rheumatoid arthritis patients. Int Immunol 9: 739743,1997

11) Sayos J, Wu C, Morra M, et al. The X-linked lymphoproliferativedisease gene product SAP regulates signals induced through the coreceptor SLAM. Nature 1; 395 (6701): 462-469, 1998.

12) Takei $M$, Ishiwata $T$, Mitamura $K$, et al. Decreased expression of signaling lymphocytic-activation molecule-associated protein (SAP) transcripts in $\mathrm{T}$ cells from patients with rheumatoid arthritis. Int Immunol 13: 559-565, 2001. 